\title{
Ex vivo Reactivity of the Ovarian Vascular Bed to Noradrenaline and Carbachol during Ovarian Hyperstimulation Syndrome
}

\author{
M.A. Oriowo \\ Department of Pharmacology and Toxicology, Faculty of Medicine, Kuwait University, Safat, Kuwait
}

\section{Key Words}

Dissociation constant · Human menopausal

gonadotropin · Noradrenaline · Ovarian artery · Ovarian hyperstimulation syndrome

\begin{abstract}
Objective: To study reactivity of the ovarian vascular bed to noradrenaline and carbachol during an experimentally induced ovarian hyperstimulation syndrome (OHSS) in rabbits. Materials and Methods: Rabbits were treated with human menopausal gonadotropin (75 IU) daily for 6 days, followed by human chorionic gonadotropin $(2,500 \mathrm{IU})$ to induce OHSS. The ovarian vascular bed was isolated and perfused with physiological solution and its reactivity to injected noradrenaline and acetylcholine was examined. Results: The mean weight of the hyperstimulated ovary was $2.85 \pm 0.5 \mathrm{~g}$ compared to $0.25 \pm 0.1 \mathrm{~g}$ for the control rabbits. There was no significant difference in (a) the basal perfusion pressure of the ovarian vascular bed ex vivo; (b) the potency of, or maximum response to, noradrenaline, and (c) agonist dissociation constant or receptor density. Carbachol induced significantly greater vasodilation in ovarian vascular beds from hormone-treated rabbits, indicating a greater
\end{abstract}

\section{KARGER}

Fax +41613061234

E-Mail karger@karger.ch

www. karger.com
(C) 2004 S. Karger AG, Basel

1011-7571/04/0133-0115\$21.00/0

Accessible online at:

www. karger.com/mpp role for nitric oxide in this syndrome, as further supported by the observation that NW-nitro-L-arginine methyl ester hydrochloride ( $L-N A M E)$ was more effective against carbachol-induced response in hormone-treated rabbits. Conclusion: In the rabbit model of OHSS, carbachol produced an increased ex vivo vascular response but noradrenaline did not.

Copyright $@ 2004$ S. Karger AG, Base

\section{Introduction}

Approximately 1-2\% of patients undergoing ovulation induction either with clomiphene or human menopausal gonadotropin (HMG) develop ovarian hyperstimulation syndrome (OHSS). The incidence of OHSS is more frequent and of greater severity in patients receiving HMG. OHSS is essentially an inflammatory response characterized by a markedly enlarged ovary, increased vascular permeability and, in the severe form, by a fluid shift from the intravascular to extravascular space, leading to ascites, pleural effusion and reduction in the intravascular volume [1]. An intense peripheral vasodilation likewise occurs [2, 3], leading to arteriolar hypotension, which in turn evokes a compensatory increase in heart rate and car-
Dr. M.A. Oriowo

Department of Pharmacology and Toxicology, Faculty of Medicine

Kuwait University, PO Box 24923

13110 Safat (Kuwait)

Tel. +965 5312300, ext. 6327, Fax +965 5342583, E-Mail oriowo@hsc.kuniv.edu.kw 
diac output. Blood flow to the ovary is remarkably increased during OHSS, associated with a reduction in vascular resistance in the ovarian vascular bed. It is, however, not known what mechanisms are responsible for the reduced ovarian vascular resistance.

OHSS is characterized by high circulating plasma levels of estrogens [4, 5]. Estrogens have been shown to induce vasodilator effects [5] via the release of endothelial nitric oxide (NO). Recent studies have shown that locally released NO modulated ovarian blood flow around the periovulatory period in rats [6] consistent with modulation of ovarian vascular responses by the endothelium [7]. This finding is supported by the observation that NWnitro- $L$-arginine methyl ester hydrochloride ( $L$-NAME), an inhibitor of NO [8], inhibits human chorionic gonadotropin (HCG)-induced increase in blood flow [6].

The ovary has a dense adrenergic innervation, with most of the nerves running alongside the blood vessels. Previous studies, using either arterial ring segments [9] or whole vascular beds [10], have shown the noradrenalineevoked dose-dependent vasoconstrictor responses in the ovarian vasculature via activation of $\alpha_{1}$-adrenoceptors [9, 10]. Vascular smooth muscle reactivity to catecholamines may be altered by a number of factors including diseases, aging and changes in hormonal states such as those that occur during pregnancy [11-14].

Prolonged exposure to catecholamines may also alter vascular smooth muscle reactivity [15-18]. Since the plasma level of noradrenaline is markedly increased during OHSS [2, 3], prolonged exposure of $\alpha_{1}$-adrenoceptors in the ovarian vascular bed to catecholamines results in receptor desensitization and down-regulation, leading to reduced reactivity of the ovarian vascular bed.

However, there are no studies on the reactivity of the ovarian vasculature to vasoactive substances during OHSS. The main objective of the present investigation therefore was to study reactivity of the ovarian vascular bed to noradrenaline and carbachol during an experimentally induced OHSS in rabbits, in an attempt to determine whether the ovarian bed perfusion characteristics of OHSS in an experimental animal model are due to inhibitory vascular reactivity to noradrenaline and/or increased endothelium-dependent NO-mediated vasodilation (carbachol-induced vasodilation is endothelium-dependent). The rabbit was chosen because ovarian hyperstimulation in rabbits is very well characterized and has been used in several studies on the pathophysiology of the OHSS [19, $20]$.

\section{Materials and Methods}

Thirty-two adult female rabbits weighing $2.5-4 \mathrm{~kg}$ were used in this study. The rabbits were maintained under standard conditions in the Animal Resource Center of the Faculty of Medicine, Kuwait University, Kuwait.

\section{Induction of OHSS}

OHSS induced using a previously described protocol $[19,20]$ is rapid and very reproducible. Briefly, each rabbit was injected intramuscularly with Pergonal ${ }^{\circledR}$ (HMG, 75 IU) daily for 6 days, and on day 6 each rabbit received an additional intramuscular injection of Pregnyl ${ }^{\circledR}$ (HCG, 2,500 IU). The rabbit was used in the study $48 \mathrm{~h}$ after the HCG injection.

\section{Isolation of the Ovarian Vascular Bed}

Each rabbit was anesthetized with sodium pentobarbitone $(50 \mathrm{mg} / \mathrm{kg}$ intravenously) and exsanguinated. The abdominal cavity was opened, the paired ovarian arteries were freed from the surrounding fatty tissue, and arterial branches were tied off. The ovarian arteries, together with the attached ovaries, were removed and placed in a Petri dish containing Krebs' solution at $37^{\circ} \mathrm{C}$. The ovarian artery was cannulated with a polyethylene cannula (PE 50) and the whole preparation was perfused with Krebs' solution $\left(37^{\circ} \mathrm{C}\right)$ at $6 \mathrm{ml} /$ min. Perfusion pressure was recorded through a pressure transducer (Lectromed SensoNor 80) connected to a Lectromed two-channel recorder.

The preparation was allowed to equilibrate for $30 \mathrm{~min}$, after which a test dose of noradrenaline was injected to test for tissue responsiveness. Thereafter, successive doses of the agonists were given as bolus injections (in a volume not exceeding $0.3 \mathrm{ml}$ ) at regular intervals to generate a dose-response curve.

\section{Determination of Agonist Dissociation Constant}

Agonist dissociation constant $\left(\mathrm{K}_{\mathrm{A}}\right)$ was determined according to the method described by Furchgott and Bursztyn [21], which involved partial receptor occlusion by treatment with an irreversible (alkylating) $\alpha_{1}$-adrenoceptor antagonist. Briefly, after obtaining a control dose-response curve for noradrenaline, the ovarian vascular bed was perfused with Krebs' solution containing phenoxybenzamine (PBZ, $10^{-9} \mathrm{M}$ ) for $30 \mathrm{~min}$, followed by perfusion with PBZfree Krebs' solution for another $30 \mathrm{~min}$ before reestablishing the noradrenaline dose-response curve. From the dose-response curves, equieffective doses of noradrenaline before $(\mathrm{A})$ and after $\left(\mathrm{A}^{1}\right)$ treatment with PBZ were obtained and used to plot a graph 1/A versus $1 / \mathrm{A}^{1}$. The slope of the regression line and the $\mathrm{Y}$ intercept were used to calculate agonist dissociation constant using the equation:

$$
\mathrm{KA}=\text { slope }-1 \text { /intercept }
$$

$\mathrm{KA}$ values are presented as $\mathrm{pK}_{\mathrm{A}}$ (where $\mathrm{pK}_{\mathrm{A}}=-\log \mathrm{K}_{\mathrm{A}}$ ). Fractional receptor occupancy (RA/RT) at each agonist concentration was calculated using the equation:

$[\mathrm{RA}] /[\mathrm{RT}]=[\mathrm{A}] /[\mathrm{A}]+\mathrm{K}_{\mathrm{A}}$

Estimates of receptor reserve were obtained from $\mathrm{K}_{\mathrm{A}} / \mathrm{EC}_{50}$ [22].

Vasodilator Responses

Noradrenaline $\left(10^{-5} \mathrm{M}\right)$ was added to the perfusion fluid to raise perfusion pressure. Once the perfusion pressure has stabilized at a new level, successive doses of carbachol were given as bolus injec- 
Fig. 1. Effect of OHSS on reactivity of the perfused rabbit isolated ovarian vascular bed to noradrenaline $(n=7)$. Inset Maximum increase in perfusion pressure induced by noradrenaline in these preparations $(\mathrm{n}=$ 7). OHSS was induced by treating rabbits with HMG (75 IU) for 6 days followed by HCG (2,500 IU) on the 6th day. Rabbits were used 2 days after HCG.

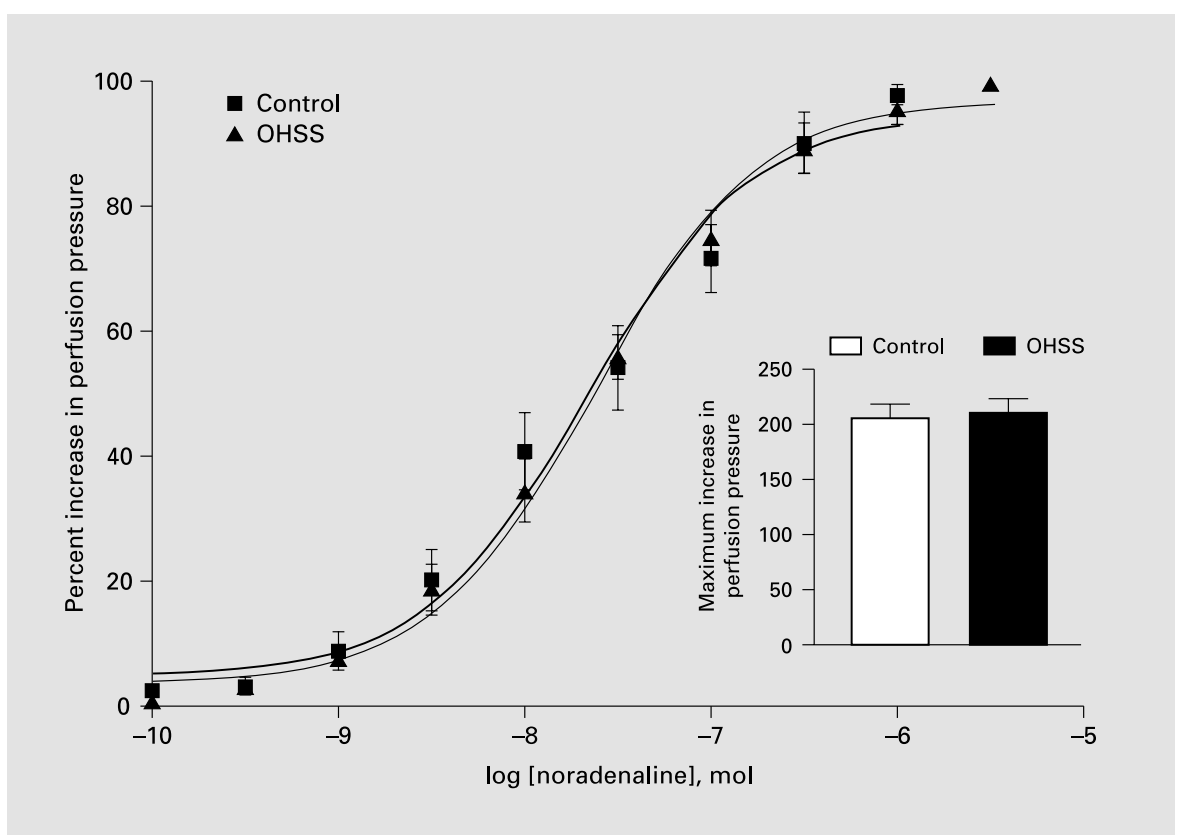

tions (in a volume not exceeding $0.3 \mathrm{ml}$ ) at regular intervals to generate a dose-response curve. Vasodilation was expressed as a percentage of noradrenaline-induced tone to compare maximum vasodilation induced by carbachol in both groups. Where the effect of $L$-NAME on carbachol-induced responses was examined, vasodilation was expressed relative to its maximum response in each preparation.

\section{Physiological Solution}

Krebs' solution $\left(37^{\circ} \mathrm{C}\right)$ was used in all experiments. The composition was as follows: $\mathrm{NaCl}, 119 ; \mathrm{KCl}, 4.7 ; \mathrm{MgCl}_{2}, 1.2 ; \mathrm{KH}_{2} \mathrm{PO}_{4}, 1.2$; $\mathrm{CaCl}_{2}, 2.5 ; \mathrm{NaHCO}_{3}, 25$, and glucose, $11.0 \mathrm{mmol} / 1$. The solution was gassed continuously with a mixture of $5 \% \mathrm{CO}_{2}$ and $95 \% \mathrm{O}_{2}$.

\section{Drugs}

The following compounds were used in this investigation: Pregnyl (HCG), (-)-arterenol (noradrenaline) bitartrate (Sigma Chemicals, St. Louis, Mo., USA), Pergonal (HMG) and phenoxybenzamine dihydrochloride, carbamoylcholine (carbachol) chloride, $L$-NAME (Research Biochemicals International, Natick, Mass., USA). Phenoxybenzamine was dissolved in absolute ethanol, while noradrenaline was dissolved in $0.1 \mathrm{~N}$ hydrochloric acid. All other compounds were dissolved in water.

\section{Data Analysis}

Agonist potencies were expressed as $\mathrm{pD}_{2}$ (negative logarithm of the agonist concentration that would produce $50 \%$ of the maximum response) values obtained from the dose-response curves. All graphs were plotted and analyzed using the Graphpad prism software. Data are presented as mean \pm SEM of ' $n$ ' experiments where ' $n$ ' represents the number of animals. Differences between mean values were tested for statistical significance using Student's t test for paired or unpaired observations as appropriate. In all cases, the difference was considered significant when $\mathrm{p}<0.05$.

Ovarian Hyperstimulation and Vascular

Reactivity

\section{Results}

All animals treated with HMG for 6 consecutive days followed by HCG on day 6 developed OHSS. None if the rabbits in the control group developed the syndrome; however, there was a significant increase in the weight of the ovaries. In the control rabbits, the mean weight was $0.25 \pm 0.10 \mathrm{~g}$, while the mean weight of the hyperstimulated ovaries was $2.88 \pm 0.50 \mathrm{~g}$, representing an approximately 10-fold increase in ovarian weight. The difference in these values was statistically significantly $(p<0.05)$. In addition, there were signs of edema and multiple luteinization in the ovaries.

\section{Vasoconstrictor Effects of Noradrenaline}

Constant basal perfusion pressure was maintained throughout the duration of each experiment (which lasted up to $5 \mathrm{~h}$ in some cases) in the ovarian vascular bed of both control and treated rabbits. There was no significant difference in the basal perfusion pressure between the controls $(43.7 \pm 6.0 \mathrm{~mm} \mathrm{Hg})$ and the treated $(44.1 \pm 6.4$ $\mathrm{mm} \mathrm{Hg})$ rabbits. Noradrenaline $\left(10^{-10}-3 \times 10^{-6} \mathrm{~mol}\right)$ produced dose-related increases in perfusion pressure (fig. 1). The maximum increase in perfusion pressure was $205.7 \pm 11.9$ and $210.7 \pm 11.8 \mathrm{~mm} \mathrm{Hg}$ in control $(\mathrm{n}=15)$ and treated $(n=19)$ rabbits, respectively, but the difference was not statistically significant $(\mathrm{p}>0.05)$. The $\mathrm{pD}_{2}$ values were $7.68 \pm 0.09$ and $7.63 \pm 0.06$ for control $(\mathrm{n}=$ 

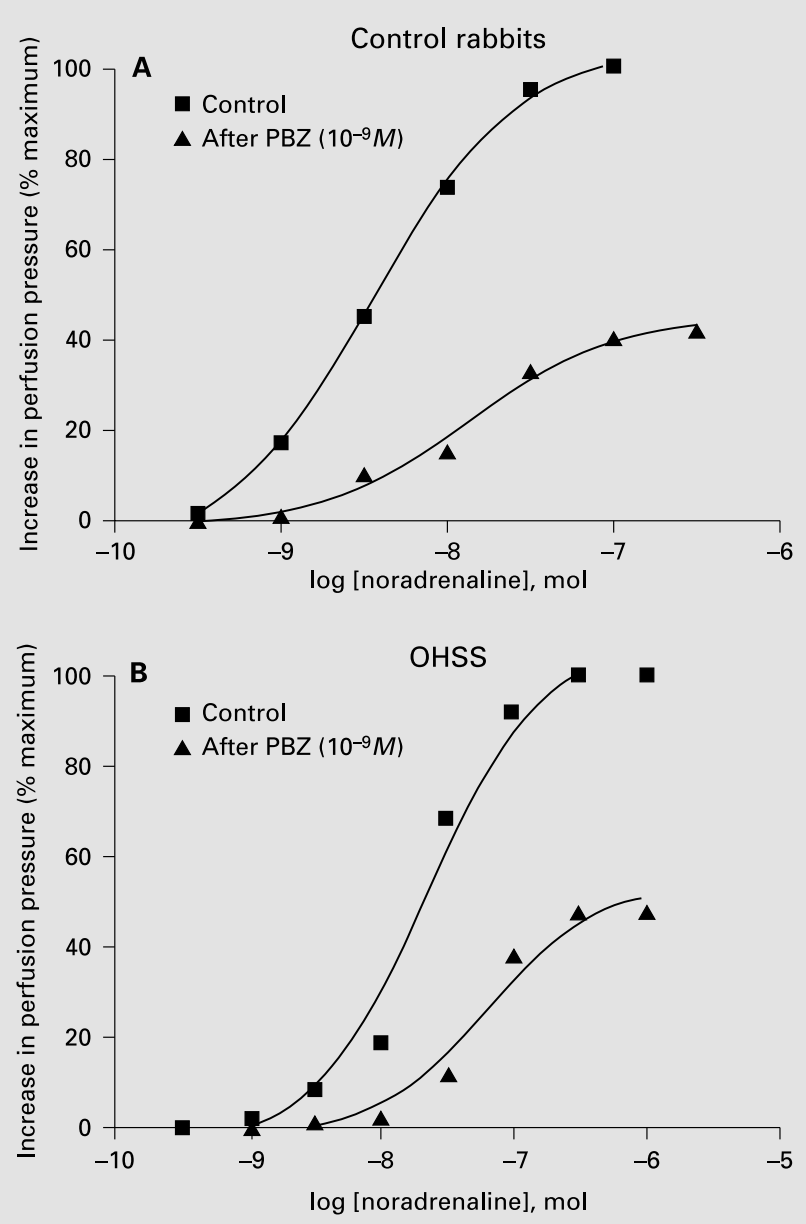

Fig. 2. Effect of phenoxybenzamine $\left(10^{-9} M\right)$ on noradrenalineinduced vasoconstrictor responses in the perfused ovarian vascular bed isolated from control (A) and OHSS (B) rabbits. PBZ was allowed to equilibrate with the tissue for $30 \mathrm{~min}$ followed by perfusion with PBZ-free Krebs' solution for another $30 \mathrm{~min}$ before reestablishing noradrenaline dose-response curves.

7) and treated $(\mathrm{n}=7)$ rabbits, respectively, again not statistically significant $(\mathrm{p}>0.05)$.

Treatment of the ovarian vascular beds with phenoxybenzamine $\left(10^{-9} M\right)$ for 15 min shifted noradrenaline dose-response curves to the right and depressed the maximum response, consistent with phenoxybenzamine being an irreversible $\alpha_{1}$-adrenoceptor antagonist as exemplified in figure 2. Apparent dissociation constants $\left(\mathrm{pK}_{\mathrm{A}}\right)$ obtained from such experiments were 7.20 \pm 0.10 and 7.10 \pm 0.10 for control $(n=7)$ and treated $(n=8)$ rabbits, respectively $(\mathrm{p}>0.05)$. The receptor reserves calculated using mean $\mathrm{pD}_{2}$ and $\mathrm{pK}_{\mathrm{A}}$ values are 3.02 and 3.39 for

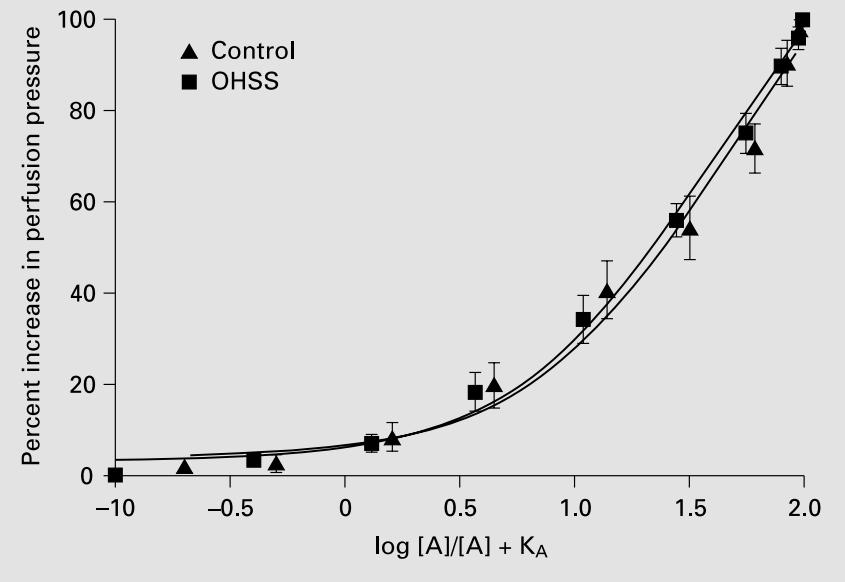

Fig. 3. Vasoconstrictor effect of noradrenaline, expressed as a function of fractional receptor occupancy, in the perfused rabbit isolated ovarian vascular bed. Each point on the graph is the mean \pm SEM of 7 experiments.

control and treated rabbits, respectively. A graph illustrating response against receptor occupancy $\left(\log [\mathrm{A}] /[\mathrm{A}]+\mathrm{K}_{\mathrm{A}}\right)$ is shown in figure 3 . The relationship between response and fractional receptor occupancy was almost linear, indicating very little receptor reserve. The fraction of the receptors occupied by noradrenaline to produce $50 \%$ of the maximum response was approximately $48 \%$ in control and $40 \%$ in hormone-treated rabbits.

\section{Vasodilator Responses}

In preparations where perfusion pressure was raised with noradrenaline $\left(10^{-5} \mathrm{M}\right)$, carbachol $\left(10^{-12}-3 \times 10^{-8}\right.$ mol) produced a reproducible dose-dependent decrease in perfusion pressure (fig. 4). The $\mathrm{pD}_{2}$ values were $6.04 \pm$ $0.19(n=5)$ and $7.64 \pm 0.07(n=6)$ in control and HMGtreated rabbits, respectively. These values were significantly different from each other $(\mathrm{p}<0.05)$. There was no difference in the maximum response to acetylcholine (100\% reversal of noradrenaline-induced tone) in HMGtreated rabbits compared with the controls. $L$-NAME $\left(3 \times 10^{-4} M\right)$ was more effective in the HMG-treated rabbits, indicating a greater contribution of NO to carbacholinduced vasodilation in the treated rabbits (fig. 5). The $\mathrm{pD}_{2}$ values were $6.04 \pm 0.19(\mathrm{n}=7)$ and $5.80 \pm 0.19(\mathrm{n}=$ 6) before and in the presence of $L$-NAME, respectively, in control rabbits, while corresponding values in HMGtreated rabbits were $7.69 \pm 0.07(n=6)$ and $5.86 \pm 0.05$ $(\mathrm{n}=6)$, respectively. Sodium nitroprusside $(\mathrm{SNP})$ also produced dose-dependent vasodilation in both groups. 


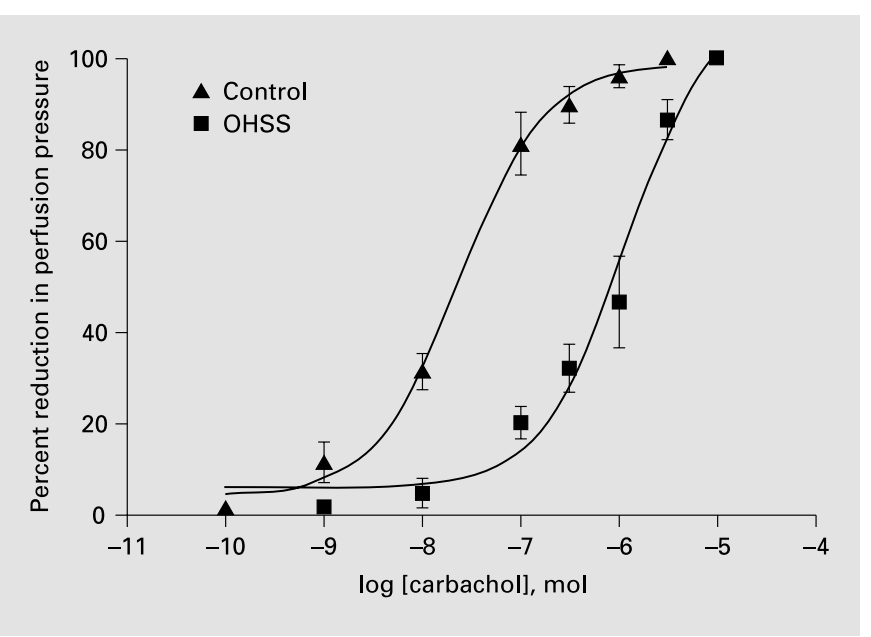

Fig. 4. Carbachol-induced vasodilator responses in isolated perfused ovarian vascular bed isolated from control $(\boldsymbol{\Delta})$ and HMG-treated (ם) rabbits. Each point on the graph is the mean \pm SEM of 5-7 experiments.

The $\mathrm{pD} 2$ values were $8.14 \pm 0.08(\mathrm{n}=6)$ in control and HMG-treated rabbits, respectively. The maximum response to SNP in control rabbits was $77.1 \pm 2.1 \%(n=8)$, while the corresponding value in HMG-treated rabbits was $75.5 \pm 6.8 \%(n=5)$. There was no significant difference in either the potency or maximum response $(\mathrm{p}>$ $0.05)$.

\section{Discussion}

Blood flow to an organ is usually determined by the balance between vasoconstrictor and vasodilator mechanisms. In OHSS, blood flow to the ovary is significantly increased, indicating that the balance is tilted towards vasodilator mechanisms. However, the factors responsible for the increased vasodilation are not known. The ovarian vascular bed has a high adrenergic innervation, and since the sympathetic nervous system plays an important role in regulating vascular smooth muscle tone, the possibility was considered that the reduced vascular resistance in the ovarian vascular bed could be due to inference from adrenergic mechanism. Reduced efficacy of $\alpha_{1^{-}}$ adrenoceptor activation could result from a reduction in receptor density/affinity or an alteration in the signal transduction mechanism. It could also be due to the release of endogenous vasodilator substances, including EDRF, which would reduce the response to adrenergic stimulation. Increased peripheral vasodilation during
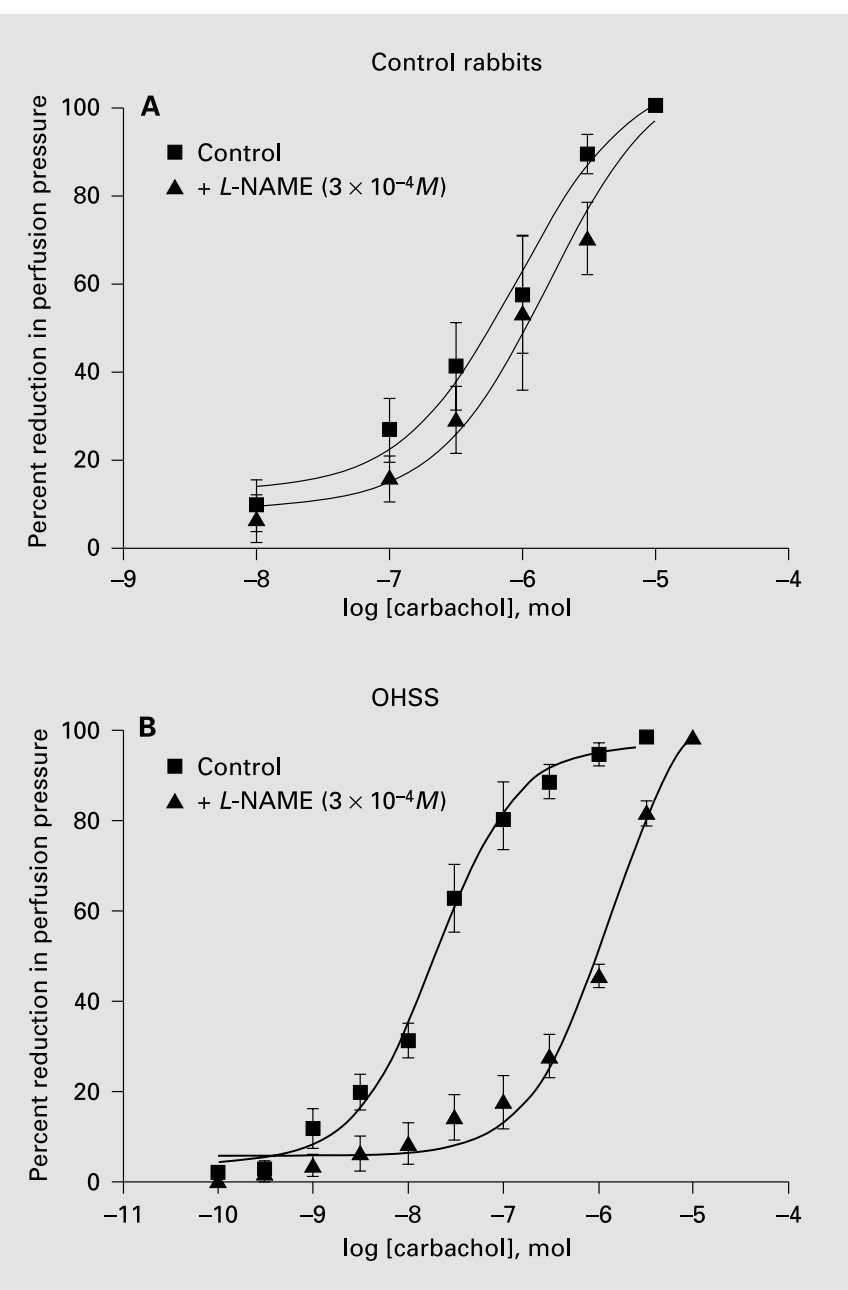

Fig. 5. Effect of $L$-NAME $\left(3 \times 10^{-4} M\right)$ on carbachol-induced vasodilation in perfused ovarian vascular bed from control (A) and OHSS (B) rabbits. $\boldsymbol{D}$ and $\boldsymbol{\Delta}$ represent carbachol-induced vasodilation before and in the presence of $L$-NAME. Each point on the graph is the mean \pm SEM of 5-7 experiments.

pregnancy has been attributed to an enhanced release of EDRF.

Previous studies in this laboratory have shown that the potency of noradrenaline in the ovarian vascular bed was not affected by blocking neuronal uptake with cocaine $\left(3 \times 10^{-6} M\right)$ or extraneuronal uptake with deoxycorticosterone acetate $\left(10^{-5} M\right)$ and $\beta$-adrenoceptors with propranolol $\left(10^{-6} M\right)$. These compounds were therefore not routinely used in this study. Results obtained in this study showed that there was no significant difference in the basal perfusion pressure between preparations from control and OHSS rabbits, consistent with the reduction in vascu- 
lar resistance observed in vivo. This observation suggests that there was no structural change in the architecture of the ovarian vessels and that the increase in vessel diameter was probably due to circulation vasodilator substance. In addition, there was no significant difference either in the potency of or the maximum vasoconstrictor response to noradrenaline in the preparations used in this study.

According to the receptor theory, the potency of an agonist is determined by the affinity of the agonist for the receptors and receptor density [22]. A situation in which a reduction in one parameter is offset by an increase in the other would leave the potency estimate unchanged. In this study, estimates of the receptor density and affinity of noradrenaline for the receptors were determined using the partial receptor occlusion method [21]. The difference between apparent dissociation constants for noradrenaline control and hormone-treated rabbits, $7.20 \pm 0.10$ and $7.10 \pm 0.01$, respectively, were not significantly different $(p>0.05)$, indicating that ovarian hyperstimulation was not associated with a reduced affinity of noradrenaline for $\alpha_{1}$-adrenoceptors in this vascular bed. Ordinarily, agonist dissociation constants are determined under conditions in which equilibrium responses to the agonists are achieved. In this study, however, since doses were given as bolus injections, the responses were not strictly 'equilibrium responses', and therefore the reported values of agonist dissociation constants are apparent dissociation constants. Since control and OHSS vascular beds were studied under identical conditions, these estimates provide an acceptable means of comparing agonist affinities in these preparations.

The results also showed that the receptor reserves, an estimate of receptor density, similar in both groups, were low (approximately 3). This finding is supported by the observation that the fractional receptor occupancy-response curve was almost linear, a characteristic of low receptor reserve state. The fact that noradrenaline occupied similar proportions of the receptors for the same level of response confirms that there was no change in $\alpha_{1}$ adrenoceptor characteristics.

The results described above would therefore suggest that agonist-induced vasoconstriction was not impaired during OHSS. It is very well recognized that continuous exposure of a receptor to its agonist results in loss of agonist potency, either due to receptor down-regulation [16, 17] or blunted phosphatidylinositol turnover [18]. The fact that the receptor reserve (an index of receptor density) was not altered by ovarian hyperstimulation would suggest that the elevated level of noradrenaline observed in OHSS was insufficient to induce down-regulation of the receptors. Alternatively, perhaps the period of exposure was not long enough to induce down-regulation of the receptors.

Furchgott and Zawadski [23] demonstrated the obligatory role of the vascular endothelium in acetylcholineinduced relaxation of the rabbit aorta. These authors showed that acetylcholine relaxed the arterial smooth muscle only when the endothelium was intact, while in endothelium-derived preparations, no vasorelaxation was observed. The endothelium-derived relaxing factor has subsequently been identified as NO [24-26]. NO has been shown to modulate vascular responses in the ovarian vascular bed [7]. In addition, locally released NO has been shown to modulate blood flow to the ovary during the process of ovulation [6].

We previously demonstrated that carbachol-induced vasodilation in the ovarian vascular bed is endotheliumdependent since the vasodilator response was abolished when the vascular endothelium was removed by perfusion with CHAPS [7]. We have also shown that both NO and a hyperpolarizing factor (EDHF), the identity of which is yet unknown, mediated carbachol-induced endothelium-dependent vasodilation in the vascular bed. Subsequent experiments, performed to determine the existence of a possible increase in endothelium-mediated vasodilation during OHSS, compared the endotheliumdependent vasodilator effects of carbachol, a muscarinic receptor agonist, in control and treated rabbits. The hypothesis was that carbachol-induced vasodilation would be greater in vascular preparations from hormonetreated rabbits than in control if OHSS were associated with an increase in EDRF release. The results showed that carbachol induced greater vasodilator responses in the treated rabbits than in controls, indicating release of a larger amount of EDRF in the treated rabbits. Vasodilation induced by SNP was similar between control and OHSS rabbits, indicating that there was no change in sensitivity of the vascular preparation to NO during OHSS.

In order to determine the relative contributions of $\mathrm{NO}$ and the EDHF to the enhanced carbachol-induced vasodilation in the rabbit OHSS ovarian bed, the effect of $L$ NAME, an inhibitor of NO synthesis, on carbacholinduced vasodilation was examined. The results showed that $L$-NAME, a NO synthase inhibitor [8], was a more effective inhibitor in treated that control rabbits, indicating a greater participation of NO in these rabbits. The fact that $L$-NAME displaced the carbachol dose-response curve to the right without depressing the maximum response might suggest that $L$-NAME probably interfered with muscarinic receptors in addition to its effect on NO 
synthesis. More studies are required to confirm this possibility. These studies would determine if (1) the enhanced vasodilation in OHSS rabbits is receptor-specific and (2) if the enhanced vasodilation is unique to muscarinic receptor agonists.

The implication of these observations is that the reduced vascular resistance in the ovarian bed during OHSS is not due to a defect in vascular smooth muscle reactivity to vasoconstrictor agents; rather, it is probably due to an increase in the level of circulating vasodilator substances. An increase in the release of NO was indicated by the greater vasodilator effect of carbachol in the treated rabbits. However, the elevated level of NO did not appear to depress noradrenaline responses in the ovarian vascular bed, possibly due to simultaneous release of a contracting factor acting to prevent the modulatory effect of NO on noradrenaline-induced contractions. We are currently investigating this possibility.

\section{Conclusion}

It was concluded that OHSS in rabbits did not modify reactivity of the ovarian vascular bed to noradrenaline. However, the vasodilator response to carbachol was increased, suggesting enhanced release of an endotheliumderived relaxing factor. $\mathrm{NO}$ appeared to play a greater role in carbachol-induced vasodilation in this syndrome.

\section{Acknowledgments}

The author is grateful to Mr. A. Cherian and Mrs. Elizabeth A. Kadavil for technical assistance. This study was supported by a Kuwait University grant MR 035.

\section{References}

1 Schenker JG, Weinstein D: Ovarian hyperstimulation syndrome: A current survey. Fertil Steril 1978;30:255-268.

2 Balasch J, Arroyo V, Carmona F, Llach J, Jimenez W, Pare JC, Vanrell JA: Severe ovarian hyperstimulation syndrome: Role of peripheral vasodilation. Fertil Steril 1991;56:10771083.

3 Balasch J, Arroyo V, Fabregues F, Salo J, Jimenez W, Pare JC, Vanrell JA: Neurohormonal and haemodynamic changes in severe cases of the ovarian hyperstimulation syndrome. Ann Intern Med 1994;121:27-33.

4 Bergh PA, Navot D: Ovarian hyperstimulation syndrome: A review of pathophysiology. J Assist Reprod Genet 1992;9:429-438.

5 Magness RR, Rosenfeld CR: Local and systemic estradiol-17ß: Effects on uterine vasodilation. Am J Physiol 1989;256:E536-542.

6 Mitsube K, Zackrisson U, Brannstrom M: Nitric oxide regulates ovarian blood flow in the rat during the periovulatory period. Hum Reprod 2002;17:2509-2516.

7 Yousif MH, Oriowo MA, Williams KI: Endothelial modulation of vasoconstrictor responses in the perfused rabbit ovarian vascular bed. Pharmacology 1999;59:106-114.

8 Moore P, Wallace P, Gaffen Z, Hart SL, Babbedge RC: Characterization of the novel nitric oxide synthase inhibitor 7-nitro indazole and related indazoles: Antinociceptive and cardiovascular effects. Br J Pharmacol 1993;110: 219-224.
9 Oriowo MA, Bevan JA: Alpha 1-adrenoceptor subtype mediates norepinephrine-induced contraction of the rabbit isolated ovarian artery. $\mathrm{J}$ Cardiovasc Pharmacol 1986;8:858-863.

10 Yousif M, Williams KI, Oriowo MA: Characterization of alpha-adrenoceptor subtype(s) mediating vasoconstriction in the perfused rabbit ovarian vascular bed. J Auton Pharmacol 1996; 16:221-227.

11 Michel MC, Brodde OE, Insel PA: Peripheral adrenergic receptors in hypertension. Hypertension 1990;16:107-120.

12 Wadsworth RM: Calcium and vascular reactivity in ageing and hypertension. J Hypertens 1990;8:975-983.

13 Gurdal H, Cai G, Johnson MD: Alpha 1-adrenoceptor responsiveness in the aging aorta. Eur J Pharmacol 1995;274:117-123.

14 Altura BM, Altura BT: Vascular smooth muscle and neurohypophyseal hormones. Fed Proc 1977;36:1853-1860.

15 Carrier O Jr, Wedell EK, Barron KW: Specific alpha-adrenergic receptor desensitization in vascular smooth muscle. Blood Vessels 1978; 15:247-258

16 Colucci W, Gimbrone M, Alexander W: Regulation of the postsynaptic adrenergic receptor in rat mesenteric artery. Circ Res 1981;48:104111.

17 Wikberg JES, Akers M, Caron MG, Hagen PO: Norepinephrine-induced down regulation of alpha 1 adrenergic receptors in cultured rabbit aorta smooth muscle cells. Life Sci 1983;33: 1409-1417.

18 Lurie KG, Tsujimoto G, Hoffman BB: Desensitization of alpha-1 adrenergic receptor-mediated vascular smooth muscle contraction. J Pharmacol Exp Ther 1985;234:147-152.
19 Gergely RZ, Paldi E, Erlik Y, Makler A: Treatment of ovarian hyperstimulation syndrome by antihistamine. Obstet Gynecol 1976;47:8385 .

20 Erlike Y, Naot Y, Friedman M, Ben-David E, Paldi E: Histamine levels in ovarian hyperstimulation syndrome. Obstet Gynecol 1979;53: 580-582.

21 Furchgott RF, Bursztyn P: Comparison of dissociation constants and of relative efficacies of selected agonists acting on parasympathetic receptors. Ann NY Acad Sci 1967;144:882-898.

22 Ruffolo RR Jr: Review of important concepts of receptor theory. J Auton Pharmacol 1982;2: 277-295.

23 Furchgott RF, Zawadski JV: The obligatory role of endothelial cells in the relaxation of arterial smooth muscle by acetylcholine. Nature 1980;288:373-376.

24 Palmer RM, Ferrige AG, Moncada S: Nitric oxide release accounts for the biological activity of endothelium-derived relaxing factor. $\mathrm{Na}$ ture 1987;327:524-526.

25 Moncada S, Radomski MW, Palmer RM: Endothelium derived relaxing faction: Identification as nitric oxide and role in the control of vascular tone and platelet function. Biochem Pharmacol 1988;37:2495-2501.

26 Moncada S, Palmer RM, Higgs EA: Nitric oxide: Physiology, pathophysiology and pharmacology. Pharmacol Rev 1991;43:109-142. 